\title{
Special issue on optimization in military applications
}

\author{
Vladimir Boginski ${ }^{1}$ • Eduardo L. Pasiliao ${ }^{2}$. \\ Siqian Shen $^{3}$
}

Received: 28 September 2015 / Accepted: 7 October 2015 / Published online: 19 October 2015

(C) Springer-Verlag Berlin Heidelberg 2015

Optimization methods have been historically applied to a wide variety of military problems, including military transportation and logistics, emergency response, sensor deployment, target detection, cyberdefense, and more. Meanwhile, the diverse problems in military and defense applications exhibit special structures and features that have inspired the development of new optimization methodologies, in particular in network optimization, game theory, stochastic and dynamic control.

The aim of this special issue was to solicit original, high-quality papers that address emerging trends and advances in the theories and applications of optimization methods for defense and national security. We have received many submissions and, after a rigorous peer review process, 18 papers were selected for publication. These papers cover problems of military resource planning, staff scheduling, dispatching, vehicle/aircraft routing, set covering, and network interdiction. The related methods vary from stochastic programming, integer programming, and convex programming, to stochastic control, machine learning, and meta-heuristics. In particular, the majority of

Vladimir Boginski

boginski@reef.ufl.edu

Eduardo L. Pasiliao

pasiliao@eglin.af.mil

Siqian Shen

siqian@umich.edu

1 Department of Industrial and Systems Engineering, Research and Engineering Education Facility (REEF), University of Florida, 1350 N Poquito Rd., Shalimar, Gainesville, FL 32579, USA

2 Munitions Directorate, Air Force Research Laboratory, 101 W. Eglin Blvd, Eglin AFB, Valparaiso, FL 32542, USA

3 Department of Industrial and Operations Engineering, University of Michigan, 1205 Beal Avenue, 2793 IOE, Ann Arbor, MI 48109, USA 
the published papers concern complex military systems, data processing, navigation, and other important military missions.

This special issue was planned in conjunction with the recently established Mathematical Modeling and Optimization Institute that is funded by the Air Force Research Laboratory (AFRL) and hosted at the University of Florida Research and Engineering Education Facility (UF-REEF) in close proximity to Eglin Air Force Base. The Institute facilitates multi-university collaborative activities in modeling and optimization research in military applications. The Institute also hosts its annual review conference at UF-REEF every summer. This conference serves as a forum for all interested researchers to present and discuss recent results on related topics. Some of the papers in this special issue have resulted from those activities. We hope that this compilation of papers will provide an informative and stimulating read to all audiences.

We would like to thank many people who offered their generous help and made this special issue possible. First, we sincerely thank the two Editors-in-Chief of the journal, Professor Pavlo Krokhmal and Professor Oleg Prokopyev, who supported the idea and entrusted us with carrying it through. Also, we would like to thank the Editorial Office for providing prompt assistance with the editorial management system. Furthermore, we thank all the authors for submitting to this special issue as a worthy outlet for their research work. Last but not least, our deepest appreciation goes to all the reviewers, who provided their valuable time and effort to perform the reviews of all the submitted manuscripts. They have given very constructive and helpful comments that led to improved presentations of many of the submitted manuscripts. 